\title{
Identity Style and Academic Burnout with Internet Addiction in Students
}

\author{
Nikpour G*, Qadimi A and Qaribzade S \\ Department of Psychology, Faculty of Psychology \& Education, Islamic Azad University, Iran \\ *Corresponding author: Nikpour G, Department of Psychology, Faculty of Psychology \& Education, Islamic Azad University, Iran; Email: nikpoorg@yahoo.com
}

Received: December 23, 2020; Accepted: December 27, 2020; Published: December 28, 2020

\begin{abstract}
Introduction: In a world becoming more complex, the necessity of using the internet for human especially students is more than ever, because the internet can play a major role in gaining mastery. Students as those who can have an important role in current situation and especially the future of a country in order to be favorable conditions for using cyberspace are undoubtedly more vulnerable to the dangers of cyberspace. Therefore, this research intends to determine whether identity styles and academic burnout are effective on internet addiction in students?

Method: To investigate this, we used the correlation research method and the Pearson and regression statistical method. And among all students of the Islamic Azad University of Sari, three sample groups were selected 155 people equally as examples and were used to collect data required from the ISI Browinsky identity questionnaire and for educational assessment of the questionnaire and to measure the Internet addiction assay from the Kimberly Young questionnaire.

Conclusion: There is a relation between identity styles and Internet addiction in students, it is found that the link between the style of identity and normative information identity with Internet addiction is negative. It may be because the use of the internet is slowly addicted to the negative attractiveness of the internet, creating the impression that it can provide psychological and emotional needs. It is also found that there is a correlation between academic exhaustion with Internet addiction and increasing the Internet addiction، Perhaps the reason for this is that the Internet addiction has the ability to recruit an individual as it tries to pay attention to the educational tasks
\end{abstract}

\section{Introduction}

Computer and internet as essential tools of life are responsible for facilitating the lives of people who have created new dangers that one of these risks is the creation of neglect or academic burnout in students [1]. In a world becoming more complex, the necessity of using the internet for human especially students is more than ever, because the internet can play a major role in gaining mastery [2]. On the other hand, anonymity appears on the internet and virtual communities to give people a chance to play with their identity or build a new identity so that they can have different personalities and affect the lifestyle of people and their types of emotions, and studies have shown that technology addiction affects the actual purposes of technology users. This is primarily due to the maladaptive understanding that is thus shaped as a result of technology addiction [3]. Also the results of research have shown that social networks lead to changes in the lifestyle of youth in the fields such as leisure time, attention and tendency to the body to how to cover, style of speech, creating conditions for communication with opposite sex and gaining ability of the day in attitude toward the world. People with low-risk seeking experience enjoy a healthier lifestyle [4]. Student as those who can play an important role in the current situation and especially the future of a country, the students are more likely to be exposed to the dangers of cyberspace to be conducive to the use of cyberspace. As the main pillar of the educational system of the country in achieving the goals of the educational system, they have a special role and status, so paying attention to this huge and young people of society, fertility and prosperity have the most educational system in society. The main objective of any educational system is to create suitable ground for learning and actualization of potential human potential. On the other hand, gaining success and learning needs to have a healthy and lively spirit and all the efforts done in the process of education tend to develop healthy personality of students [5]. Considering the negative role of internet addiction in the desire to educate [6] and also the role of internet addiction in reducing academic performance [7], this research intends to determine whether the style of identity and academic burnout with internet addiction is effective in students? In this regard, by reviewing the literature and literature, some basic hypotheses have been formed and that there is a relationship between identity styles and internet addiction. Also there is relation between identity styles and academic burnout in students. And some other research hypotheses...

\section{Method and Result}

To examine this issue, correlation research method and the Pearson and regression statistical method was used. Of all students of the Islamic Azad University of Sari, three sample groups were selected 155 people equally as examples. To collect data required from the ISI Brownsky identity style questionnaires and for educational assessment 
academic burnout questionnaire, and the extent to which Internet addiction Kimberly Young questionnaire has been used, and finally to investigate the first process of research using Pearson correlation test, the following techniques were extracted.

\begin{tabular}{|l|l|c|c|c|}
\hline Styles & Number & $\begin{array}{c}\text { Coefficient of } \\
\text { correlation }\end{array}$ & $\begin{array}{c}\text { Research } \\
\text { coefficient }\end{array}$ & $\begin{array}{c}\text { Probability } \\
\text { value }\end{array}$ \\
\hline Information identity style & 155 & -0.454 & 0.206 & 0.000 \\
\hline Normative identity style & 155 & -0.426 & 0.181 & 0.000 \\
\hline Confused identity style & 155 & -0.464 & 0.215 & 0.000 \\
\hline
\end{tabular}

On the basis of these data, the relationship between identity styles and internet addiction is confirmed and also for the study of the second process, the relationship between academic burnout and internet addiction has been used and the following data were extracted.

\begin{tabular}{|l|l|l|l|}
\hline Variable & Number & Coefficient of correlation & Probability value \\
\hline Academic burnout & 155 & 0.461 & 0.000 \\
\hline
\end{tabular}

Accordingly, the relationship between academic burnout and internet addiction is confirmed.

To investigate the relationship between identity styles and academic burnout, Pearson correlation statistical method was used.

\begin{tabular}{|l|c|c|c|c|}
\hline Styles & Number & $\begin{array}{c}\text { Coefficient of } \\
\text { correlation }\end{array}$ & $\begin{array}{c}\text { Determination } \\
\text { coefficient }\end{array}$ & $\begin{array}{c}\text { Probability } \\
\text { value }\end{array}$ \\
\hline Information identity style & 155 & -0.460 & 0.184 & 0.000 \\
\hline Normative identity style & 155 & -0.420 & 0.176 & 0.000 \\
\hline Confused identity style & 155 & -0.467 & 0.218 & 0.000 \\
\hline
\end{tabular}

According to the above data, the relationship between identity styles with academic burnout is also confirmed.

It is also used to examine the fourth hypothesis, each of the identity styles in the prediction of Internet addiction in different students from a step- by- step analysis method between identity styles and Internet addiction. And the result has shown that each of the identity styles is different in explaining Internet addiction.

\section{Conclusion}

The main purpose of this study was to investigate the relationship between identity styles and academic burnout with internet addiction in Azad university students. According to the proposed hypotheses, we discuss each of these hypotheses. The first hypothesis is that there is a relationship between identity styles and internet addiction among students, it was found that the relationship between informational and normative identity style with internet addiction is negative, This finding is inconsistent with Jamshidei and Sarvqad's [8] findings, and its direction is positive in relation to the confused identity with the Internet addiction that aligns with findings of Jamshidei and Sarvqad [8] and Piri [9] and Kamali et al. [10]. The reason for this can be explained by Dastjerdi's [11] research under the title An Investigation of the role of Cyber Networks in Cultural Identity of Students at the University of Isfahan, based on the false attractiveness of the internet, which creates the impression that it can provide psychological and emotional needs.

Therefore, replacing social networks on the internet instead of presence and interaction with people in the real world will cause users social and emotional relationships to be disrupted.
In the study of the second hypothesis that academic exhaustion with Internet addiction has been found on students, there is a relationship between them. The results of this study are based on the results of Ganji [6] and Pourmirzai [7] based on the negative role of addiction to internet and performance and education; in explaining this, it can be concluded Jin et al. [12] and Shahbaziyan [1] researches; that there is a positive and significant relationship between procrastination in preparing academic term papers with dependence on internet and a negative and significant relationship with academic self- efficacy. Procrastination in preparing for the exam is not correlated with Internet dependence and academic efficiency, but between Internet dependence and academic self-efficacy plays a major role in predicting the degree of Internet dependence, and in the second step, procrastination in homework could play a significant role. Based on the findings, male students reported more Internet dependence than female students, which is in line with the process presented in this section. In examining the third hypothesis; Based on that; there is a relationship between identity styles and academic burnout in students, according to the results, it was found that there is a negative relationship between informational and normative identity style and academic burnout. In the context of this finding based on Bruce [13] results, it can be said that stress and avoidance of academic burnout that several factors such as social support failure, stress over size and personality traits can be the cause of academic burnout. The fourth hypothesis is that the contribution of each identity style to internet addiction is different in students. In examining the fourth hypothesis that the contribution of each identity style in predicting Internet addiction in students is different. The data show that identity styles are simultaneously effective in the occurrence of Internet addiction and the share of each identity style among Internet addiction is different, which can be concluded based on the results of Sadeghi and et al. [14] and Thomas [15] explained. According to this study, identity style has a significant negative relationship with information identity with Internet addiction and confused identity style has a positive relationship with Internet addiction, and therefore the relationship between normative identity style and Internet addiction is not significant.

\section{References}

1. Shabaziyan A (2017) Distinguish between students with academic procrastination and ordinary students based on Internet addiction. Daneshvar Medicine 131: 1-10.

2. Sindermann C, Peterka J, Sha P, Zho M, Montag C (2019) The relationship between internet use disorder, depression and burnout among Chinese and German college students. Addictive Behaviors 89: 188-99.

3. Chen L, Nath R (2016) Understanding the underlying factors of Internet addiction across culture. Electronic Commerce Research and Applications 17: 38-48.

4. Muchacka A, Tomaszek K (2020) Examinating the relationship between student school burnout and problematic internet use. Education Sciences 20: 16-31.

5. Bahadori J, Hashemi $\mathrm{T}$ (2012) Internet attachment styles, coping strategies and mental health with Internet addiction. Iranian Developmental Psychology 8: 177-188.

6. Ganji B, Asadi S, Babak F (2016) Investigating the relationship between Internet addiction and students' academic motivation. Journal of Educational Strategies in Medical Sciences 9:150-155.

7. Pourmirzai H, Asgari G (2017) Predicting Internet Addiction as a Factor Affecting Academic Performance Based on D-Personality Type and Humorous Styles in Medical Students. Iranian Journal of Medical Education 17: 1-10. 
8. Jamshidi M, Sarvqad S (2015) The mediating role of identity styles in relationship between differentiation of self and internet addiction. Journal of psychological methods and models 6: 37-54.

9. Piri Z, Amiri M (2019) The mediating role of coping strategies in the relationship between emotion difficulty and Internet addiction. Ofogh Danesh Scientific Research Journal 26: 38-53.

10. Kamali N, Houseini F (2020) A study of the relationship between neuroticism and Internet addiction among young people. Study of Borazjan Azad University students. Bushehr Disciplinary Science Quarterly 10: 69-75.

11. Dastjerdi N (2014) An investigation of the role of Cyber network in cultural identity of students at the university of Isfahan. Applied Sociology 25: 159-70.
12. Liu S, Jin C (2018) The relationship between college students mobile phone addiction and learning burnout: personality as a moderator. Chinese Journal of Special Education 2: 86-91.

13. Bruce S (2016) Recognizing stress and avoiding Burnout. Currents in Pharmacy Teaching and Learning 1: 57-64.

14. Doostani P, Sadeghi A (2019) Predicting career goal discrepancy based on careerrelated stress, career goal feedback, and field of study in students. Journal of Counseling Research 17: 22-43.

15. Thomas D (2016) Cellphone addiction and academic stress among university students in Thailand. International Forum 19: 80-96.

\section{Citation:}

Nikpour G, Qadimi A, Qaribzade S (2020) Identity Style and Academic Burnout with Internet Addiction in Students. Ageing Sci Ment Health Stud Volume 4(1): 1-3. 